УДК 314.1:330:351.746

\title{
ДЕМОГРАФИЧЕСКИЙ АСПЕКТ ЭКОНОМИЧЕСКОЙ БЕЗОПАСНОСТИ ГОСУДАРСТВА
}

\author{
Анофриков Сергей Павлович, \\ anofrikov@rambler.ru \\ Афончикова Вера Алексеевна, \\ dacnsk@gmail.com
}

Новосибирский государственный университет экономики и управления, Россия, 630099, г. Новосибирск, ул. Каменская, 52/1

Анофриков Сергей Павлович, кандидат экономических наук, заведующий кафедрой общественных финансов Новосибирского государственного университета экономики и управления.

Афончикова Вера Алексеевна, старший преподаватель кафедры общественных финансов Новосибирского государственного университета экономики и управления.

\begin{abstract}
Актуальность исследования определяется тем, что на современном этапе развития международных отношений экономическая безопасность государства становится ключевым фактором при принятии стратегических решений. Государство, заботящееся о своем будущем, обязано учитывать численность и качество своих трудовых ресурсов и населения в целом. Цель: рассмотреть влияние демографической составляющей на уровень экономической безопасности государства. Методы: сравнительно-сопоставительный анализ статистических и научных материалов, анализ процесса старения населения. Результаты. Рассмотрены нормативно-правовые акты, посвященные вопросам экономической безопасности и демографической политики государства, представлены данные о старении населения в России и в мире, приведены показатели суммарного коэффициента рождаемости, коэффициента демографической нагрузки пожилыми и коэффициента перспективной демографической нагрузки пожилыми людьми, а также показатели миграционного прироста населения России. Сформулирован общий вывод о существенном влиянии демографической составляющей на экономическую безопасность государства.
\end{abstract}

Ключевые слова: Экономическая безопасность, демография, продолжительность жизни, старение населения.

В мировой научной литературе понятие экономической безопасности исследуется достаточно давно. При этом выделяется несколько подходов к ее определению [1]. Но несмотря на различие точек зрения относительно терминологии, все авторы подчеркивают значимость данного явления в современных условиях. Действительно, процесс глобализации накладывает свой отпечаток на условия функционирования национальных экономик, уровень жизни населения в них, возможность самостоятельного принятия стратегических решений тем или иным государством.

Однако в российской практике данная категория на законодательном уровне была закреплена только в 2017 г. С одной стороны, это говорит о некотором отставании российской нормативно-правовой базы от вызовов времени, с другой - это еще раз подчеркивает, что на современном этапе развития международных отношений нормальное функционирование экономики нашего государства объективно невозможно без четко определенной системы ориентиров экономической безопасности.

Согласно Указу Президента РФ от 31.12.2015 № 683 «О Стратегии национальной безопасности Российской Федерации» национальная безопасность - это «состояние 
защищенности личности, общества и государства от внутренних и внешних угроз, при котором обеспечиваются реализация конституционных прав и свобод граждан Российской Федерации (далее - граждане), достойные качество и уровень их жизни, суверенитет, независимость, государственная и территориальная целостность, устойчивое социально-экономическое развитие Российской Федерации» [2].

Данным Указом выделяются следующие виды безопасности: государственная, общественная, информационная, экологическая, экономическая, транспортная, энергетическая и безопасность личности. Обеспечение национальной безопасности рассматривается через призму стратегических национальных приоритетов, таких как: оборона страны, государственная и общественная безопасность, повышение качества жизни российских граждан, экономический рост, наука, технологии и образование, здравоохранение, культура, экология живых систем и рациональное природопользование, стратегическая стабильность и равноправное стратегическое партнерство.

Указом Президента РФ от 13.05.2017 № 208 «О Стратегии экономической безопасности Российской Федерации на период до 2030 года» был определен ряд понятий, в том числе и понятие экономической безопасности: «экономическая безопасность состояние защищенности национальной экономики от внешних и внутренних угроз, при котором обеспечиваются экономический суверенитет страны, единство ее экономического пространства, условия для реализации стратегических национальных приоритетов Российской Федерации» [3]. Кроме этого, данным документом были определены понятия экономического суверенитета, национальных интересов, угроз и вызовов экономической безопасности, рисков в области экономической безопасности и обеспечения экономической безопасности. Были обозначены показатели состояния экономической безопасности, один из которых - доля населения трудоспособного возраста в общей численности населения.

Важно понимать, что система критериев экономической безопасности не ограничивается только экономическими показателями, о чем нам говорит включение демографического показателя в стратегию экономической безопасности.

Достаточное количество трудоспособного населения и высококвалифицированных кадров являются необходимым условием в достижении экономической безопасности и благосостояния страны. В свою очередь, благосостояние страны влияет на рост численности населения, повышение качества его жизни и увеличение продолжительности жизни.

Указом Президента РФ от 09.10.2007 № 1351 была утверждена Концепция демографической политики Российской Федерации на период до 2025 года [4], а распоряжением Правительства РФ от 14.04.2016 № 669-р утвержден план мероприятий, направленный на реализацию данной Концепции в 2016-2020 гг. В рамках указанного плана утверждались такие мероприятия, как мероприятия по повышению рождаемости, по снижению предотвратимых причин смертности, по снижению материнской и младенческой смертности, улучшению репродуктивного здоровья, по снижению смертности за счет улучшения условий и охраны труда, по формированию мотивации к здоровому образу жизни, занятию физкультурой и спортом и по регулированию миграции в соответствии с социально-экономическими потребностями Российской Федерации.

Некоторыми ожидаемыми результатами данного плана, связанными с мероприятиями по повышению рождаемости, увеличением продолжительности жизни и миграционными процессами выступают:

1) повышение суммарного коэффициента рождаемости с 1,78 в 2015 г. до 1,87 в 2020 г.; 
2) рост ожидаемой продолжительности жизни с 71,4 года в 2015 г. до 74 лет в 2020 $\Gamma . ;$

3) миграционный прирост на уровне не менее 200 тыс. человек в 2020 г. [5].

Несмотря на то, что до конца обозначенного периода еще остается некоторое время, уже сейчас можно определить общую динамику данных показателей.

Суммарный коэффициент рождаемости с 2015 по 2018 г. в РФ вместо запланированного роста снизился с 1,777 до 1,579 и согласно даже оптимистическому прогнозу Федеральной службы государственной статистики к 2035 г. не достигнет значения 1,87. При самом благоприятном стечении обстоятельств к 2035 г. суммарный коэффициент рождаемости составит 1,738, а при низком варианте и вовсе снизится до 1,370 [6]. Как известно, суммарный коэффициент рождаемости отражает число детей в расчете на одну женщину и на текущий момент находится ниже уровня простого воспроизводства населения, что является одной из причин сокращения численности населения.

Ситуация со вторым показателем несколько лучше. Ожидаемая продолжительность жизни, которая в 2015 г. составляла 71,39 года, в 2018 г. в РФ составила 72,91 года для всего населения. Запланированный правительством к 2020 г. уровень ожидаемой продолжительности жизни по данным демографического прогноза Федеральной службы государственной статистики будет достигнут лишь к 2025 г. по низкому варианту прогноза и к 2021 г. - по среднему варианту прогноза. Важно отметить, что это общий усреднённый показатель для мужчин и женщин. Ожидаемая продолжительность жизни в 74 года для мужчин достигается только по высокому варианту прогноза. Однако наблюдается увеличение ожидаемой продолжительности жизни, что является положительным моментом. В 2008 г. этот показатель для мужчин составлял 61,92 года, для женщин 74,28. К 2018 г. ожидаемая продолжительность жизни для мужчин составляла уже 67,75 лет, а для женщин - 77,82 [7]. Увеличение продолжительности жизни - важный фактор в решении проблемы демографической составляющей экономической безопасности. Однако увеличение продолжительности жизни положительно сказывается на состоянии экономики государства при условии соответствующего прироста молодого населения в этой стране (за счет повышения рождаемости или миграции). В противном случае повышение продолжительности жизни приводит к проблеме старения населения.

Согласно данным, представленным в докладе отдела народонаселения Департамента по экономическим и социальным вопросам Организации Объединенных Наций «Мировое население стареет 2019», общее количество населения в возрасте 65 лет и старше на 2019 г. в РФ составило 22,02 млн чел., а на 2030 г. прогнозируется увлечение данного показателя до 28,10 млн. Таким образом, доля пожилых людей по прогнозам в РФ увеличится с 15,1 \% в 2019 г. до 19,6 \% в 2030 г.

Однако старение населения является проблемой не только Российской Федерации, но и всего мира. По данным обозначенного выше доклада в 2019 г. количество людей в мире в возрасте 65 лет и старше составляло 702,9 млн чел., а в 2050 г. (через 30 лет) достигнет 1,55 млдр. Наибольший прирост пожилых людей прогнозируется в регионах Северной Африки и Западной Азии [8].

Наблюдается следующая тенденция: по мере старения населения доля лиц трудоспособного возраста (от 25 до 64 лет) и старше увеличивается, а доля детей (от 0 до 14 лет) и молодежи (от 15 до 24 лет) уменьшается.

Так в 1990 г. люди трудоспособного возраста составляли наибольшую долю всего мирового населения (42\%), за ними следовали дети в возрасте от 0 до 14 лет (33\%), молодежь в возрасте от 15 до 24 лет (19\%) и пожилые люди в возрасте 65 лет и старше (6 \%). Но с 1990 по 2050 г. прогнозируется увеличение доли пожилых людей с 6 до 16 \%, 
увеличение доли населения трудоспособного возраста с 42 до 49 \%, сокращение количества детей с 33 до 21 \% и сокращение доли молодёжи с 19 до 14 \%.

Также во всех регионах мира, особенно в Восточной и Юго-Восточной Азии, а также в Латинской Америке и странах Карибского бассейна растет коэффициент демографической нагрузки пожилыми. Он представляет собой результат деления численности населения в возрасте от 65 лет на численность населения в возрасте от 20 до 64 лет, умноженный на 100.

В РФ коэффициент демографической нагрузки пожилыми на 2019 г. составляет 24,3 \%. На 2030 г. прогнозируемое значение данного коэффициента - 34,7 \%. Наиболее близкие страны к РФ по данному показателю на 2019 г. - Белоруссия (24,1 \%), Ирландия $(24,4 \%)$, Куба $(24,9 \%)[8]$.

Страной с самым высоким показателем коэффициента демографической нагрузки пожилыми согласно докладу ООН является Япония (51 \%), далее идут страны с коэффициентом около $40 \%$ - Финляндия $(39,2 \%)$ и Италия $(39,0)$. Один из самых неблагоприятных прогнозов по росту коэффициента демографической нагрузки пожилыми дается для Китая (в частности для Гонконга) и Республики Корея. В целом (за редким исключением) уровень этого показателя выше в странах с высоким уровнем дохода и ниже в странах с низким уровнем дохода. Показатели коэффициента демографической нагрузки пожилыми для ряда стран отражены в табл. 1.

таблица 1. Коэффициент демографической нагрузки пожилыми [8]

Table 1. Old-age dependency ratio [8]

\begin{tabular}{|c|c|c|}
\hline Страны, регионы/Countries, regions & 2019 & 2030 \\
\hline \multicolumn{3}{|c|}{ Регионы с самым высоким уровнем показателя/Top regions } \\
\hline Европа/Europe & 31,3 & 40,6 \\
\hline Северная Америка/North America & 27,7 & 36,4 \\
\hline \multicolumn{3}{|c|}{ Страны с самым высоким уровнем показателя/Тор countries } \\
\hline Япония/Japan & 51,0 & 57,7 \\
\hline Финляндия/Finland & 39,2 & 47,5 \\
\hline Италия/Italy & 39,0 & 49,5 \\
\hline \multicolumn{3}{|c|}{$\begin{array}{l}\text { Российская Федерация и страны, близкие по уровню показателя } \\
\text { Russian Federation and countries close in terms of indicator }\end{array}$} \\
\hline Куба/Cuba & 24,9 & 37,0 \\
\hline Ирландия/Ireland & 24,4 & 31,1 \\
\hline Российская Федерация/Russian Federation & 24,3 & 34,7 \\
\hline Белоруссия/Belarus & 24,1 & 36,2 \\
\hline \multicolumn{3}{|c|}{ Регионы с самым низким уровнем показателя/Regions with the lowest rate } \\
\hline Африка/Africa & 7,6 & 8,4 \\
\hline \multicolumn{3}{|c|}{ Страны с самым низким уровнем показателя/Countries with the lowest rate } \\
\hline Катар/Qatar & 1,9 & 6,0 \\
\hline Объединенные Арабские Эмираты/United Arab Emirates & 1,4 & 6,8 \\
\hline
\end{tabular}

Стоит отметить, что на фоне увеличения доли пожилого населения, рост которого приводит к увеличению коэффициента демографической нагрузки, одновременно наблюдается и рост продолжительности жизни, а также рост продолжительности здоровой жизни. В связи с этим такие исследователи, как Е.М. Щербакова [9] и А.Г. Вишневский [10], прибегают к показателям, опирающимся не на фактический возраст населения, а на продолжительность жизни. Здесь мы подходим к понятию «порог старости», которое обеспечивает гибкий подход к определению, кого считать пожилыми людьми.

Данный подход предполагает, что не все люди становятся пожилыми, достигая возраста 65 лет (или любого другого фиксированного возраста). Согласно мнению данных 
исследователей, порог старости зависит от состояния здоровья, физического, интеллектуального, психологического состояния.

Чаще всего за порог старости принимают возраст, в котором средняя ожидаемая продолжительность жизни становится меньше 15 лет [11].

В 2018 г. ожидаемая продолжительность предстоящей жизни по Российской Федерации для мужчин, достигших возраста 60 лет, составляла 16,56 лет, для женщин, достигших возраста 55 лет, - 26,28. Наблюдается положительная динамика данного показателя (в 2005 г. он составлял 13,26 и 22,85 для мужчин и женщин соответственно). И согласно таблицам смертности по Российской Федерации возраст, в котором ожидаемая продолжительность жизни составляет менее 15 лет, для мужчин в 2018 г. -65 лет $(13,78)$, для женщин - 70 лет $(14,38)$. Этот возраст можно считать порогом старости для РФ на 2018 г. [12].

Если говорить о более точном значении данного показателя, то в исследовании Российской академии народного хозяйства и государственной службы (РАНХиГС) совместно с Международным институтом прикладного системного анализа (IIASA) и Федеральной службой государственной статистики «Регионы России на демографической карте 2019» для 2017 г. порог старости в РФ для мужчин составляет 62,6 года, а для женщин - 69 лет.

Страны с аналогичным порогом старости для мужчин - Ливия, Малави, Замбия, с аналогичным порогом старости для женщин - Алжир, Венгрия, Катар [13].

Одним из показателей, рассчитываемых на основе порога старости, является коэффициент перспективной демографической нагрузки пожилыми - число лиц старше возраста, в котором ожидаемая продолжительность жизни составляет 15 лет, к числу лиц в возрасте от 20 лет до возраста, в котором ожидаемая продолжительность жизни составляет 15 лет, умноженное на 100.

Согласно данным доклада ООН коэффициент перспективной демографической нагрузки для Российской Федерации в 2019 г. составляет 19,3 \% и в дальнейшем будет увеличиваться, а к 2030 г. достигнет 25,9\%. На данный момент наиболее близкие по этому показателю для РФ такие страны, как Молдова (19,4 \%), Финляндия (19,2 \%) и Швеция (19,2\%) [8].

Значение коэффициента перспективной демографической нагрузки пожилыми для ряда стран отражено в табл. 2.

В Японии (стране с самым высоким коэффициентом демографической нагрузки) коэффициент перспективной демографической нагрузки в 2019 г. составлял 21,8 \%, в 2030 г. ожидается рост этого показателя до 27,9\%.

По данным Организации экономического сотрудничества и развития в Японии один из самых высоких показателей ожидаемой продолжительности жизни - в 65 лет. Для женщин в 2017 г. он составлял 24,4 года, для мужчин - 19,6 лет [14]. При этом на фоне увеличения продолжительности жизни в Японии наблюдается снижение рождаемости. Население Японии сокращается рекордными темпами [15]. Старение населения в этой стране происходит гораздо быстрее, чем в большинстве других стран ОЭСР. Данная тенденция в течение следующих 20-30 лет приведет к резкому сокращению рабочей силы.

Организация экономического сотрудничества и развития одним из вариантов решения этой проблемы видит увеличение занятости пожилых людей [16].

Безусловно, снижение прироста численности населения или отрицательный прирост частично компенсируются за счет увеличения продолжительности жизни, но этого 
недостаточно для решения глобальной проблемы старения населения и как следствие уменьшения в дальнейшем количества трудоспособного населения.

Таблица 2. Коэффициент перспективной демографической нагрузки пожилыми [8] Table 2. Prospective of old-age dependency ratio [8]

\begin{tabular}{|c|c|c|}
\hline Страна, регион/Country, region & 2019 & 2030 \\
\hline \multicolumn{3}{|c|}{ Регионы с самым высоким уровнем показателя/Top regions } \\
\hline Европа/Europe & 19,2 & 22,6 \\
\hline \multicolumn{3}{|c|}{ Страны с самым высоким уровнем показателя/Тор countries } \\
\hline Болгария/Bulgaria & 30,1 & 32,3 \\
\hline Сербия/Serbia & 27,1 & 29,0 \\
\hline Украина/Ukraine & 25,7 & 29,5 \\
\hline Хорватия/Croatia & 25,0 & 28,5 \\
\hline \multicolumn{3}{|c|}{$\begin{array}{c}\text { Российская Федерация и страны, близкие по уровню показателя } \\
\text { Russian Federation and countries close in terms of indicator }\end{array}$} \\
\hline Молдова/Moldova & 19,4 & 25,7 \\
\hline Российская Федерация/Russian Federation & 19,3 & 25,9 \\
\hline Финляндия/Finland & 19,2 & 24,5 \\
\hline Швеция/Sweden & 19,2 & 21,2 \\
\hline \multicolumn{3}{|c|}{ Регионы с самым низким уровнем показателя/Regions with the lowest rate } \\
\hline Африка/Africa & 9,5 & 9,4 \\
\hline Латинская Америка и Карибский бассейн/Latin America and the Caribbean & 9,2 & 11,2 \\
\hline \multicolumn{3}{|c|}{ Страны с самым низким уровнем показателя/Countries with the lowest rate } \\
\hline Объединенные Арабские Эмираты/United Arab Emirates & 1,0 & 3,3 \\
\hline Катар/Qatar & 0,9 & 2,2 \\
\hline
\end{tabular}

Так же как и для Японии, для России депопуляция и старение населения относятся к числу главных вызовов, на которые еще только предстоит ответить. Сложившаяся ситуация требует приспособления всех экономических и социальных институтов к новым для России демографическим условиям.

Необходим переход к интенсивным формам развития, но даже с его учетом проблемы стабилизации численности населения, по мнению некоторых авторов, не могут быть решены без использования такого инструмента, как иммиграция [17].

Согласно данным официальной статистики, представленным в табл. 3, миграционный прирост в России в 2015 г. составлял 245384 чел., в 2016 г. - 261 948, в 2017 г. - 211 878, в 2018 г. - 124 854. Таким образом, наблюдается ярко выраженная тенденция к сокращению миграционного прироста. В том числе это происходит из-за увеличивающегося в последние годы количества выбывших из России в зарубежные страны. В целом за последние 10 лет среднее значение данного показателя находилось на уроне 240000 чел. в год. Естественно, этого недостаточно для решения проблемы старения населения. К тому же, как показывает практика, в Россию наблюдается приток трудовых ресурсов не лучшего качества.

Нужно иметь в виду, что иммиграция - это инструмент не лишенный своих отрицательных последствий.

Именно поэтому в Японии данная мера не пользуется общественной популярностью [15]. Хотя изменение миграционной политики - снятие или смягчение ограничений по привлечению в эту страну трудовых мигрантов для удовлетворения возрастающей потребности в трудовых ресурсах - является возможным выходом из сложившейся ситуации.

Обозначенные выше демографические проблемы отрицательно влияют на состояние экономической безопасности государства, т. к. возникает необходимость 
обеспечения увеличивающегося пожилого населения за счет сокращающегося населения в трудоспособном возрасте.

Таблица 3. Миграционный прирост в Российской Федерации 2008-2018 г2. [18] Table 3. Net migration for the Russian Federation 2008-2018 [18]

\begin{tabular}{|c|c|c|c|}
\hline Годы/Years & $\begin{array}{c}\text { Прибывшие из зарубежных } \\
\text { стран, чел. } \\
\text { Arriving from foreign countries, } \\
\text { people }\end{array}$ & $\begin{array}{c}\text { Выбывшие в зарубежные } \\
\text { страны, чел. } \\
\text { Departed to foreign countries, } \\
\text { people }\end{array}$ & $\begin{array}{c}\text { Миграционный при- } \\
\text { рост, чел. } \\
\text { Net migration, people }\end{array}$ \\
\hline 2008 & 281614 & 39508 & 242106 \\
\hline 2009 & 279907 & 32458 & 247449 \\
\hline 2010 & 191656 & 33578 & 158078 \\
\hline 2011 & 356535 & 36774 & 319761 \\
\hline 2012 & 417681 & 122751 & 294930 \\
\hline 2013 & 482241 & 186382 & 270036 \\
\hline 2014 & 578511 & 308475 & 245384 \\
\hline 2015 & 598617 & 353233 & 261948 \\
\hline 2016 & 575158 & 313210 & 211878 \\
\hline 2017 & 589033 & 377155 & 124854 \\
\hline 2018 & 565685 & 440831 & \\
\hline
\end{tabular}

Показателем, иллюстрирующим данную ситуацию, может выступать экономический коэффициент демографической нагрузки пожилыми, данные о котором представлены в табл. 4. Он отражает долю расходов людей старше 65 лет в общих трудовых доходах населения. В РФ этот показатель в 2019 г. составлял 27,3 \% (из всех трудовых доходов на обеспечение пожилых людей уходило 27,3 \%), к 2030 г. это значение возрастет до 38,6 \% [8]. Такой рост показателя говорит о возникновении дополнительной нагрузки на пенсионную систему государства.

таблица 4. Экономический коэффициент демографической нагрузки пожилыми [8] Table 4. Economic old-age dependency ratio [8]

\begin{tabular}{|c|c|c|}
\hline Страна, регион/Country, Region & 2019 & 2030 \\
\hline \multicolumn{3}{|c|}{ Регионы с самым высоким уровнем показателя/Top regions } \\
\hline Северная Америка/North America & 42,5 & 54,8 \\
\hline Европа/Europe & 41,5 & 54,1 \\
\hline \multicolumn{3}{|c|}{ Страны с самым высоким уровнем показателя/Top countries } \\
\hline Япония/Japan & 77,7 & 90,5 \\
\hline Финляндия/Finland & 57,2 & 70,4 \\
\hline Франция/France & 54,5 & 67,9 \\
\hline Германия/Germany & 54,4 & 72,0 \\
\hline \multicolumn{3}{|c|}{$\begin{array}{c}\text { Российская Федерация и страны, близкие по уровню показателя } \\
\text { Russian Federation and countries close in terms of indicator }\end{array}$} \\
\hline Барбадос/Barbados & 28,2 & 39,3 \\
\hline Албания/Albania & 28,1 & 40,2 \\
\hline Российская Федерация/Russian Federation & 27,3 & 38,6 \\
\hline Тайвань/Taiwan & 26,9 & 44,9 \\
\hline \multicolumn{3}{|c|}{ Регионы с самым низким уровнем показателя/Regions with the lowest rate } \\
\hline Африка/Africa & 8,2 & 9,0 \\
\hline \multicolumn{3}{|c|}{ Страны с самым низким уровнем показателя/Countries with the lowest rate } \\
\hline Катар/Qatar & 2,3 & 7,1 \\
\hline Объединенные Арабские Эмираты/United Arab Em & 1,7 & 8,4 \\
\hline
\end{tabular}

Проблему устойчивости пенсионных систем разные страны решают по-разному, например прибегают к сокращению пенсионных пособий, повышению пенсионного 
возраста, проводят пенсионные реформы (например, пенсионная реформа 2008 г. в Чили, реформа, проведенная в Италии в 2012 г.) [19].

Кроме этого, среди экономических последствий старения населения выделяют такие, как изменение в структуре сбережений и инвестиций, сдвиги относительных цен под влиянием новой структуры спроса, увеличение государственных расходов на пенсии и здравоохранение [20], в целом влияние старения населения на устойчивость пенсионных систем.

На основе вышеизложенного можно утверждать, что демографические проблемы в существенной степени определяют уровень экономической безопасности государства и правительство, заботящееся о будущем страны, должно уделять вопросам демографии пристальное внимание.

\section{СПИСОК ЛИТЕРАТУРЫ}

1. Анофриков С.П., Афончикова В.А., Дукарт С.А. Финансовый аспект экономической безопасности региона (на примере Новосибирской области) // Вестник науки Сибири. - 2018. - № 4 (31). - С. 219-229. URL: http://jwt.su/journal/article/view/850/857 (дата обращения 27.01.2020).

2. О Стратегии национальной безопасности Российской Федерации: Указ Президента РФ от 31.12.2015 № 683. URL: http://www.consultant.ru/document/cons_doc_LAW_191669/ (дата обращения 27.01.2020).

3. О Стратегии экономической безопасности Российской Федерации на период до 2030 года: Указ Президента РФ от 13.05.2017 № 208. URL: http://www.consultant.ru/document/cons_doc_LAW_216629/ (дата обращения 30.01.2020).

4. Об утверждении Концепции демографической политики Российской Федерации на период до 2025 года: Указ Президента РФ от 09.10.2007 № 1351 (ред. от 01.07.2014). URL: http://www.consultant.ru/ document/cons_doc_LAW_71673/7a46cb13de731db3333fcd77a4f7887e468287e3/ (дата обращения 30.01.2020).

5. Об утверждении плана мероприятий по реализации в 2016-2020 годах Концепции демографической политики Российской Федерации на период до 2025 года: распоряжение Правительства РФ от 14.04.2016 № 669-p. URL: http://www.consultant.ru/document/cons_doc_LAW_196992/ (дата обращения 29.01.2020).

6. Суммарный коэффициент рождаемости. URL: https://www.gks.ru/storage/mediabank/progn6.xls (дата обращения 29.01.2020).

7. Ожидаемая продолжительность жизни при рождении. URL: https://www.gks.ru/storage/mediabank/ demo26.xlsx (дата обращения 03.01.2020).

8. World Population Ageing 2019: Highlights. - NY: United Nations. Department of Economic and Social Affairs, Population Division, 2019. - 38 p. URL: https://www.un.org/en/development/desa/population/ publications/pdf/ageing/WorldPopulationAgeing2019-Highlights.pdf (дата обращения 01.01.2020).

9. Щербакова Е.М. Старение населения мира по оценкам ООН 2019 года // ДЕМОСКОП WEEKLY. URL: http://www.demoscope.ru/weekly/2019/0837/barom05.php (дата обращения 04.01.2020).

10. Вишневский А.Г., Васин С.А., Рамонов А.В. Продолжительность жизни и возраст выхода на пенсию // ДЕМОСКОП WEEKLY. URL: http://www.demoscope.ru/weekly/2012/0511/tema04.php (дата обращения 05.01.2020).

11. Население России 2010-2011. Восемнадцатый-девятнадцатый ежегодный демографический доклад / под ред. А.Г. Вишневского. - М.: НИУ ВШЭ, 2013. -530 с.

12. Основные показатели таблиц смертности. URL: https://gks.ru/bgd/regl/B19_16/IssWWW.exe/Stg/5.3.xls (дата обращения 10.01.2020).

13. Регионы России на демографической карте мира. URL: https://iiasa.ac.at/web/home/research/researchPrograms/WorldPopulation/PublicationsMediaCoverage/ModelsData/Russian_DataSheet2019suppl_new.pdf (дата обращения 11.01.2020).

14. Life expectancy at 65 . URL: https://data.oecd.org/healthstat/life-expectancy-at-65.htm (дата обращения 09.01.2020).

15. Кобец П.Н., Ильин И.В. Проблемы влияния демографического кризиса в Японии на экономическую безопасность страны // Юридическая наука и практика: Вестник Нижегородской академии МВД России. - 2019. - № 3 (47). - С.130-137.

16. Ageing and employment policies. Working better with age: Japan. Executive summary and assessment and recommendations. URL: https://www.oecd-ilibrary.org/social-issues-migration-health/working-better-withage-japan_9789264201996-en (дата обращения 07.01.2020). 
17. Демографическая модернизация России, 1900-2000 / под ред. А.Г. Вишневского. - М.: Новое издательство, 2006. - $601 \mathrm{c.}$

18. Общие итоги миграции населения. URL: https://gks.ru/bgd/regl/B19_16/IssWWW.exe/Stg/7.1.xls (дата обращения 12.01.2020).

19. Taxation in aging societies: increasing the effectiveness and fairness of pension systems / A. Redonda, V. Galasso, M. Mazur, M. Stewart, M. Whittaker. URL: https://www.g20-insights.org/wp-content/uploads/2019/05/t20-japan-tf10-3-taxation-in-aging-societies.pdf (дата обращения 10.01.2020).

20. Nerlich C., Schroth J. The economic impact of population ageing and pension reforms // ECB Economic Bulletin.-2018.-V.2.-P. 85-109. URL: https://www.ecb.europa.eu/pub/pdf/other/ ebart201802_02. en.pdf (дата обращения 10.01.2020).

Поступила 20.02.2020 г. 
UDC 314.1:330:351.746

\title{
DEMOGRAPHIC ASPECT OF ECONOMIC SECURITY OF THE STATE
}

\author{
Sergey P. Anofrikov, \\ anofrikov@rambler.ru \\ Vera A. Afonchikova, \\ dacnsk@gmail.com
}

\begin{abstract}
Novosibirsk State University of Economics and Management, 52/1, Kamenskaya street, Novosibirsk, 630099, Russia.
\end{abstract}

Sergey P. Anofrikov, Cand. Sc., head of the department of public finances, Novosibirsk State University of Economics and Management

Vera A. Afonchikova, senior lecturer, Novosibirsk State University of Economics and Management.

At the present stage of development of international relations, the phenomenon of economic security of the state becomes a key concept in strategic decisions. The state, caring for its future, is obliged to take into account the number and quality of its labor resources and the population as a whole. The main aim of the research is to consider the impact of the demographic component on the level of economic security of the state. Methods: comparative analysis of statistical and scientific materials, analysis of the population aging. Results. The authors have considered the legal acts on the issues of economic security and the demographic policy of the state. The paper presents the data on population aging in Russia and in the world. The total fertility rate, the old-age dependency ratio and the prospective old-age dependency ratio are given. The net migration of Russia is considered. The paper states the general conclusion on the significant impact of the demographic component on the economic security of the state.

Key words: Economic security, demography, life expectancy, population ageing.

\section{REFERENCES}

21. Anofrikov S.P., Afonchikova V.A., Dukart S.A. Financial aspect of economic security of the region (on the example of the Novosibirsk region). Siberian Journal of Science, 2018, no. 4 (31), pp. 219-229. In Rus. Available at: http://jwt.su/journal/article/view/850/857 (accessed 27 January 2020).

22. Strategii natsionalnoy bezopasnosti Rossiyskoy Federatsii [On the National Security Strategy of the Russian Federation]. Ukaz Prezidenta RF ot 31.12.2015 no. 683. [Decree of the President of the Russian Federation of December 31, 2015 N 683]. Available at: http://www.consultant.ru/document/cons_doc_LAW_191669/ (accessed 27 January 2020).

23. O Strategii economicheskoy bezopasnosti Rossiyskoy Federatsii na period do 2030 goda [On the Strategy for the Economic Security of the Russian Federation for the period until 2030]. Ukaz Prezidenta RF ot 13.05.2017 no. 208 [Decree of the President of the Russian Federation of 05.13.2017 N 208]. Available at: http://www.consultant.ru/document/cons_doc_LAW_216629/(accessed 30 January 2020).

24. Ob utverzhdenii Kontseptsii demograficheskoy politiki Rossiyskoy Federatsii na period do 2025 goda [On approval of the Concept of the demographic policy of the Russian Federation for the period until 2025]. Ukaz Prezidenta RF ot 09.10.2007 no. 1351 (red. ot 01.07.2014). [Decree of the President of the Russian Federation of 09.10.2007 N 1351 (as amended on 07/01/2014)]. Available at: http://www.consultant.ru/document/cons_doc_LAW_71673/7a46cb13de731db3333fcd77a4f7887e468287e3/ (accessed 30 January 2020).

25. Ob utverzhdenii plana meropriyatiy po realizatsii v 2016-2020 godakh Kontseptsii demograficheskoy politiki Rossiyskoy Federatsii na period do 2025 goda [On approval of the action plan for implementation in 20162020 of the Concept of the demographic policy of the Russian Federation for the period until 2025]. Rasporyazhenie Pravitelstva RF ot 14.04.2016 no. 669-p [Order of the Government of the Russian Federation 
of April 14, 2016 N 669-r]. Available at: http://www.consultant.ru/document/cons_doc_LAW_196992/ (accessed 29 January 2020).

26. Summarny koeffitsient rozhdaemosti [The total fertility rate]. Available at: https://www.gks.ru/storage/ mediabank/progn6.xls (accessed 29 January 2020).

27. Ozhidaemaya prodolzhitelnost zhizni pri rozhdenii [Life expectancy at birth]. Available at: https://www.gks.ru/storage/mediabank/demo26.xlsx (accessed 3 January 2020).

28. World Population Ageing 2019: Highlights. NY, United Nations. Department of Economic and Social Affairs, Population Division, 2019. 38 p. Available at: https://www.un.org/en/development/desa/ population/publications/pdf/ageing/WorldPopulationAgeing2019-Highlights.pdf (accessed 1 January 2020).

29. Shcherbakova E.M. Starenie naseleniya mira po otsenkam OON 2019 goda [World population aging estimated by UN 2019]. DEMOSKOP WEEKLY. Available at: http://www.demoscope.ru/weekly/2019/0837/ barom05.php (accessed 4 January 2020).

30. Vishnevskiy A.G., Vasin S.A., Ramonov A.V. Prodolzhitelnost zhizni i vozrast vykhoda na pensiyu [Life expectancy and retirement age]. DEMOSKOP WEEKLY. Available at: http://www.demoscope.ru/weekly/ 2012/0511/tema04.php (accessed 5 January 2020).

31. Naselenie Rossii 2010-2011. Vosemnadtsaty-devyatnadtsatyy ezhegodny demograficheckiy doklad [The population of Russia 2010-2011. Eighteenth-nineteenth annual demographic report]. Ed. by A.G. Vishnevskiy. Moscow, NIU VShE Publ., 2013. 530 p.

32. Osnovnye pokazateli tablits smertnosti [The main indicators of mortality tables]. Available at: https://gks.ru/bgd/regl/B19_16/IssWWW.exe/Stg/5.3.xls (accessed 10 January 2020).

33. Regiony Rossii na demograficheskoy karte mira [Russian regions on the World demographic map 2019]. Available at: https://iiasa.ac.at/web/home/research/researchPrograms/WorldPopulation/PublicationsMediaCoverage/ ModelsData/Russian_DataSheet2019suppl_new.pdf (accessed 11 January 2020).

34. Life expectancy at 65 . Available at: https://data.oecd.org/healthstat/life-expectancy-at-65.htm (accessed 9 January 2020).

35. Kobets P.N., Ilyin I.V. Problems of the impact of the demographic crisis in Japan on the economic security of the country. Journal of Nizhny Novgorod Academy of the Ministry of Internal Affairs of Russia, 2019, no. 3 (47), pp. 130-137. In Rus.

36. Ageing and employment policies. Working better with age: Japan. Executive summary and assessment and recommendations. Available at: https://www.oecd-ilibrary.org/social-issues-migration-health/working-better-with-age-japan_9789264201996-en (accessed 7 January 2020).

37. Demograficheskaya modernizatsiya Rossii [Demographic modernization of Russia]. Moscow, Novoe izdatelstvo Publ., 2006. 601 p.

38. Obshchie itogi migratsii naseleniya [General results of population migration]. Available at: https://gks.ru/bgd/regl/B19_16/IssWWW.exe/Stg/7.1.xls (accessed 12 January 2020).

39. Redonda A., Galasso V., Mazur M., Stewart M., Whittaker M. Taxation in aging societies: increasing the effectiveness and fairness of pension systems. Available at: https://www.g20-insights.org/wp-content/uploads/2019/05/t20-japan-tf10-3-taxation-in-aging-societies.pdf (accessed 10 January 2020).

40. Nerlich C., Schroth J. The economic impact of population ageing and pension reforms. ECB Economic Bulletin, 2018, vol. 2, pp. 85-109. Available at: https://www.ecb.europa.eu/pub/pdf/other/ebart201802_02.en.pdf (accessed 10 January 2020).

Received: 20 February 2020. 